P

elas informaçð̄es ${ }^{(1)}$ que recebemos através da tradição e de diversos escritos antigos temos conhecimento sobre a deficiência física desde Homero, o mais antigo e famoso dos grandes poetas gregos, que era cego. Na llíada, revela-nos algumas particularidades a respeito de Hefesto, de sua deficiência física nas pernas e suas grandes habilidades em metalurgia e artes manuais. Cita pessoas portadoras de deficiência, desempenhando funçð̌es com enorme sucesso. Existem inúmeros exemplos de pessoas que transformaram a deficiência física, ampliando, cada vez mais, as capacidades que lhes restaram.

A atividade de arte-reabilitação é um desdobramento de minha vida artística como gravadora e desenhista, e fruto de minha vivência com crianças e jovens deficientes físicos. Este trabalho tem me ensinado muito a respeito de mim mesma e das incógnitas da própria vida, onde, nas sessores de arte, sou facilitadora do acontecimento artístico. O cotidiano com essas crianças e jovens foi colocando a arte como uma possibilidade de trabalho muito rica, dada a sua "matéria-prima" peculiar. Vislumbrei, através deste tipo de atividade num centro de reabilitação, um caminho de descoberta num campo artístico. Este encantamento levou-me a querer saber sempre mais a respeito da deficiência, suscitou novas questoes que me incentivam a investigar soluções para os problemas.

A paixão primeira, intuitiva, pela arte da "criança defeituosa" foi dando lugar a um trabalho mais paciente, mais maduro, mais voltado para os dados concretos, procurando entender melhor todo o processo da expressão plástica da criança deficiente.

$\mathrm{Na}$ Associação de Assistênciaà Criança Defeituosa (AACD), trabalhamos com arte, compondo a equipe multidisci- plinar de reabilitação. A reabilitação é um processo médico social educacional que tem como objetivo recuperar pessoas incapacitadas por diferentes causas, comoacidentes ou doenças, e reconduzílas a uma vida independente.

A arte-reabilitação trabalha através de várias formas de expressão artística, desenvolvendo as potencialidades sensório-motoras, perceptivas, cognitivas e simbólicas. A arte favorece ainda a expansão do pensamento, dos sentimentos, dos valores e torna-os patentes, presentes nas formas mais variadas de representação: pintura, música, dramatização, escultura, poesia.

Quando, há alguns anos, um jovem portador de paralisia cerebral foi impedido de entrar numa Galeria de Arte, me dei conta da situação social que a comunidade impōe à milhares de indivíduos portadores de deficiência e quanto se faz necessário preparar a sociedade para receber a pessoa deficiente. Constitui-se um direito oferecer condiçбes iguais de educação, cultura e lazer aos deficientes através de projetos educacionais e culturais especificos.

As necessidades humanas mais profundas tornam-se muito claras em um Centro de Reabilitação. O valor terapêutico de todas as atividades criativas consiste na ação global que estas exercem sobre a personalidade, sendo benéfico a todas as pessoas.

Trabalhamos com grupos de crianças e jovens com diferentes diagnósticos: paralisia cerebral (nossa maior população), mielomeningocele, doença degenerativa do sistema nervoso central, amiotrofia, malformação congênita, entre outras. Algumas crianças apresentam deficiênciamúltipla. Conseqüentemente apresentam problemas de tônus muscular, coordenação motora, equilíbrio, sensibilidade, taticidade, percepção, propriocepção, exterocepção, esteriognosia,

\title{
A arte em um centro de reabilitação
}

Ana Alice Francisquetti

Artista plástica, gravadora e desenhista. Arte reabilitadora na AACD - São Paulo 


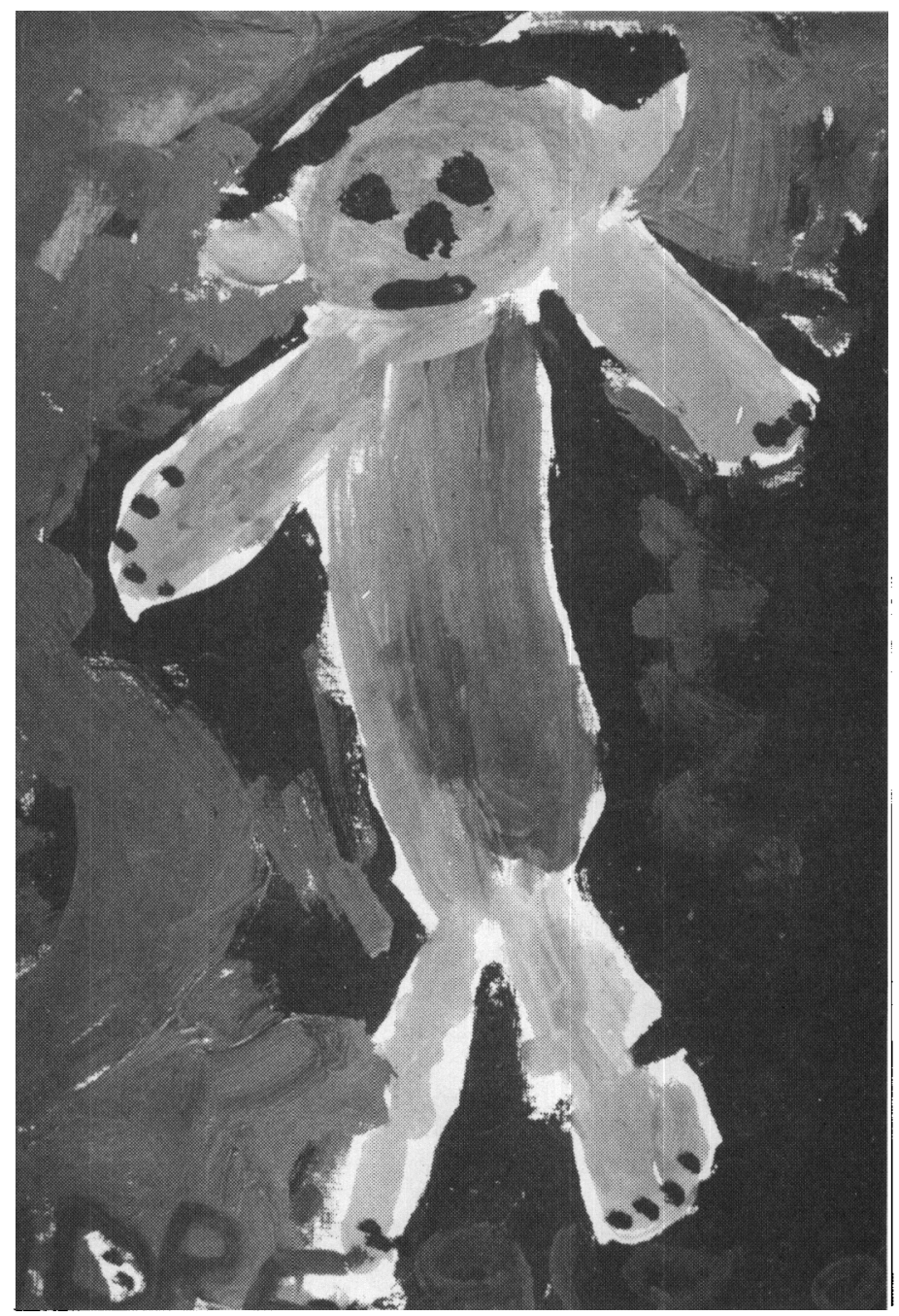

agnosia, apraxia, falta de atenção, perserveração, falta de iniciativa, insegurança, impulsividade, agressividade, inibição e, em alguns casos, rebaixamento mental. Em função destes transtornos pode-se entender melhor as dificuldades enfrentadas por uma criança deficiente e que, apesar dessas alteraçōes, consegue realizar suas atividades artísticas. Cada paciente responde às propostas de arte de acordo com seu desenvolvimento mental e capacidade física.

A literatura sobre a arte da pessoa deficiente física é bastante restrita, por entender a maioria dos pesquisadores que, dadas as dificuldades motoras, tais pessoas não conseguem desenhar, pintar, etc. Exceção feita, entre outras, ao Dr. Donald Uhlin (1979) Tugaro (1985) Di Leo (1973).

Na área da arte-reabilitação não basta proporcionarmos situaçōes motivadoras, é necessário fazer adaptaçōes tanto ao nivel individual-corporal como no espaço físico, para que se possa obter respostas, da maneira apropriada, aos estímulos. Temos algumas crianças dependentes, que fazem uso da cadeira de rodas e por vezes necessitam de auxílio físico de outra pessoa para desenhar, uma vez que atendemos também aos casos mais graves, por entender que as crianças devem vivenciar todas as fases do desenvolvimento infantil. Às vezes, temos crianças ou jovens semi-indenpendentes que fazem uso de órteses ou aparelhos ortopédicos e, outros ainda, independentes.

A concepção de que a criança defici-

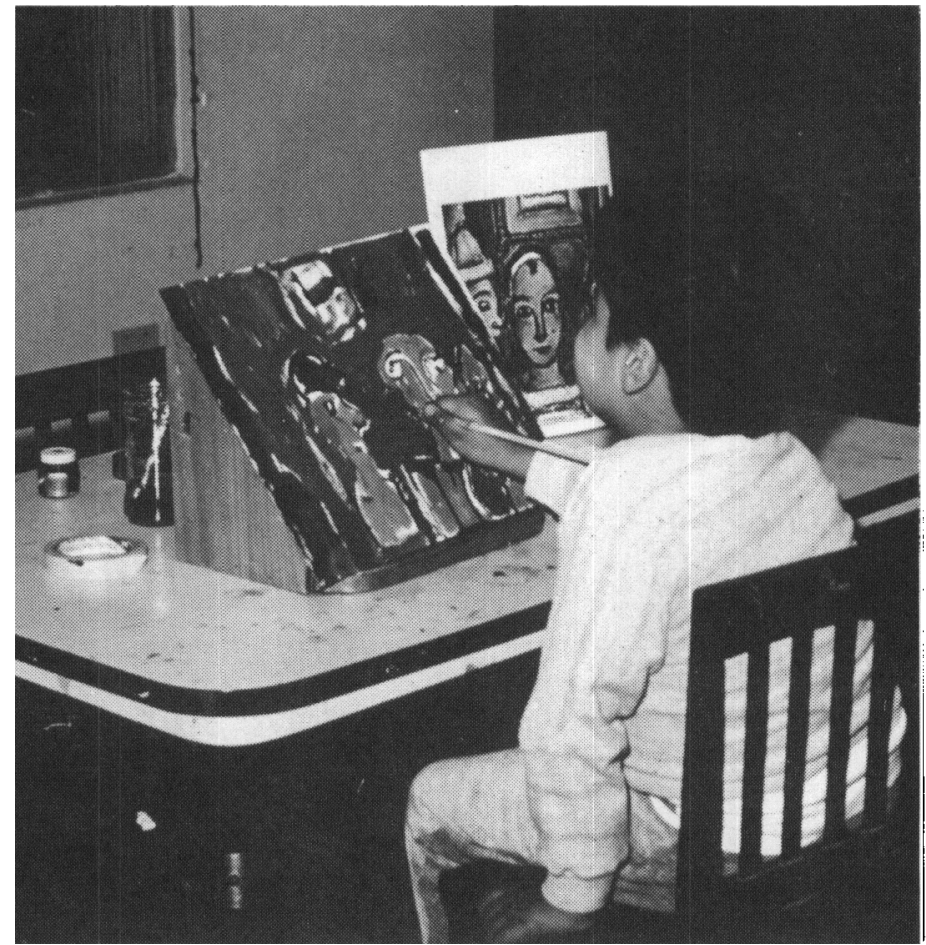
ente é incapaz de certas habilidades limita possibilidades de expressão naquelas em que outras formas de representação estão reduzidas. Um atento observador de um grupo de crianças na sessăo de arte poderá verificar que, mesmo trabalhando com o auxílio físico de outra pessoa, elas desenvolvem uma série de experiências, observam e compreendem que sentimentos e idéias podem ser expressos através de formas, cores, texturas, o que nos faz lembrar o caso do artista plástico Antonio Lizarraga, que trabalha em arte com o auxilio físico de outra profissional na área. No dizer da artista plástica Regina Silveira "A arte é uma questāo de idéias e não de gestualidade". 
Odesenho ou a pintura tem caráter de atividade lúdica, de jogo, produzindo imensa satisfação na criança, também devido à sensação de movimento do corpo e à percepção dos efeitos gráficos produzidos. Nas sessões de arte, a criança sabe que não terá que competir, que tem ampla liberdade de expressar seus sentimentos e que pode fazer uso construtivo de seu próprio envolvimentoemocional. Uma das principais vantagens da arte-reabilitação é levar a criança a ter baixa resistência à terapia, por fazer uso de materiais cheios de magia: tintas coloridas saem dos tubos adquirindo formas, pincéis de diferentes tamanhos, papéis coloridos com as mais diversas texturas.

Feitas essas considerações iniciais, passo a falar de uma criança, que chamarei de " $A$ ", foi atendida individualmente em sessões semanais de 1 hora de duração. Reunimos, ao longo de dois anos, uma série de 50 desenhos que exprimem sua evolução.

Dados colhidos em prontuários: data de nascimento 20-5-78, com diagnóstico de paralisia cerebral, diplegia atáxico moderada; história de hipertensão arterial materna desde o $5^{\circ}$ mês de gestação; sofrimento fetal; desenvolvimento neuropsicomotor atrasado e ficava em pé com base alargada sem apoio. A criança tinha grande dificuldade de comunicação. Aprendeu a ler sozinha a partir dos 3 anos de idade, freqüentou os setores de fisioterapia, terapia ocupacional, fonoaudiologia, pedagogia e o escolar. Apresentavaainda transtornos motores, balanceios, gestos irregulares, distúrbios de comportamento, agressividade e bom coeficiente intelectual. Fez arte-reabilitação nos anos de 1985 a 1986.

A família negava a deficiência e demonstrava um exagero frente ao potencial de inteligência da criança.

Nosso objetivo, pela arte, foi a conscientização da imagem corporal, ajudálo a perceber limites, ter maiores experiências cognitivas e sociais através da manipulação do fazer artístico, do contato com trabalhos de outras crianças e com obras de pintores famosos.

Em nosso primeiro encontro, parame aproximar da criança, desenhei carinhas em nossos dedos polegares. Eles se cumprimentaram e conversaram. "A" ria da brincadeira e fazia sinal positivo com o polegar. Tínhamos estabelecido assim uma ponte para nosso relacionamento. $O$ gesto de levantar o polegar foi, durante toda nossa convivência, a forma de dizermos "tudo bem". Usei-o em diferentes situações em que " $A$ " se apresentava mais inquieto ou agressivo.

Suas primeiras pinturas apresentaramse completamente caóticas. Entre os potes de tinta guache de várias cores, preferia o preto para se expressar. Borrava o papel com manchas que progressivamente o levavam a entrar numa movimentação facial frenética. Ultrapassava as bordas do papel, sem limites de espaço. Fazia círculos primitivos agrupando-os, encobria sempre os desenhos com letras de fôrma de maneira aleatória, cobrias as páginas com características gráficas, da esquerda para a direita, da direita para a esquerda, de baixo para cima e vice-versa (fig. 1,2).

\section{Figura 1}

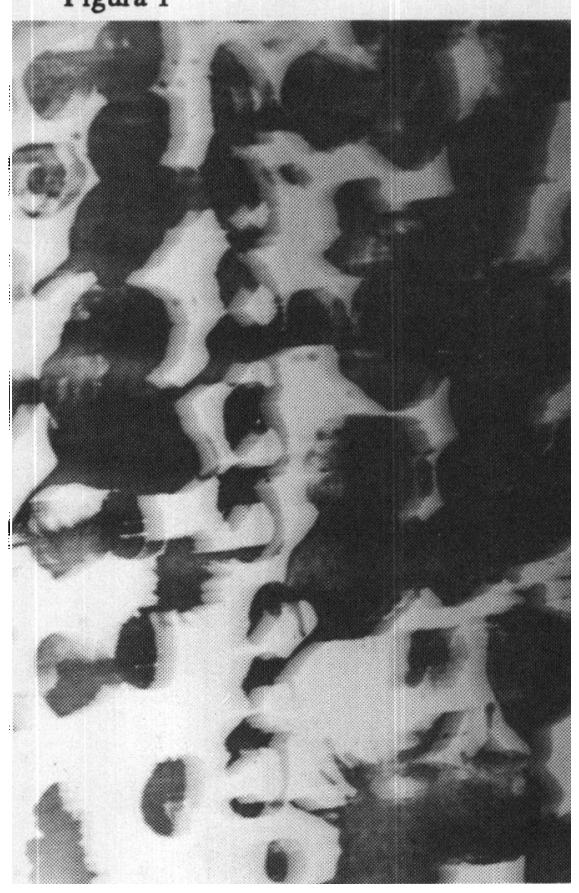

"Suas primeiras

pinturas

apresentaram-se caóticas"

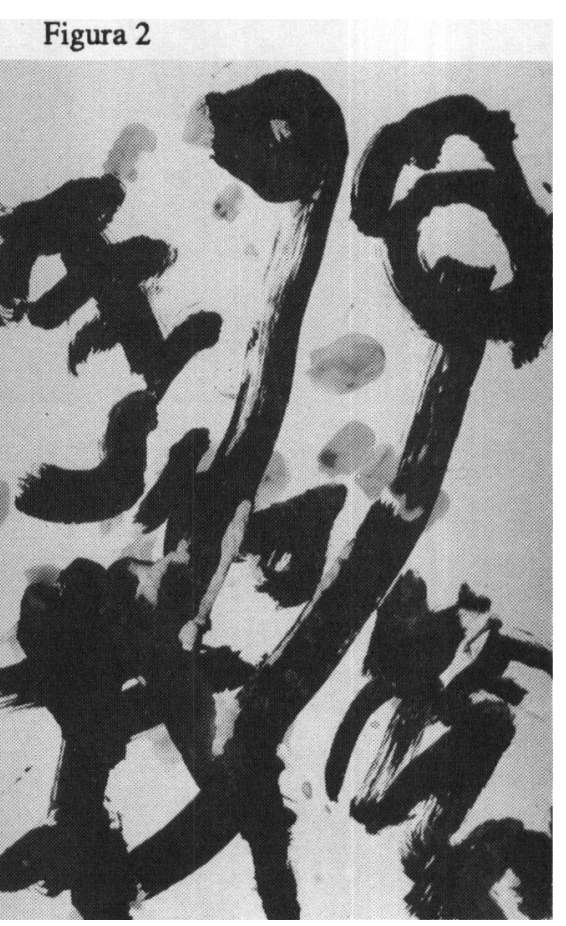

"Entre os potes de tinta guache de várias cores, preferia o preto para se expressar" 


\section{Figura 3}

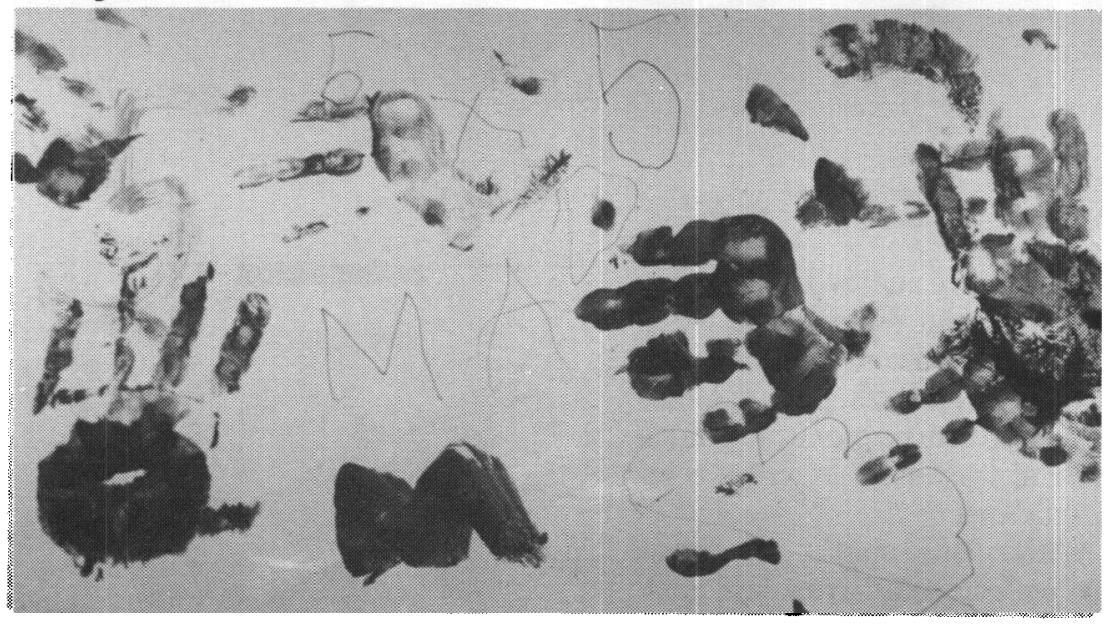

Figura 4

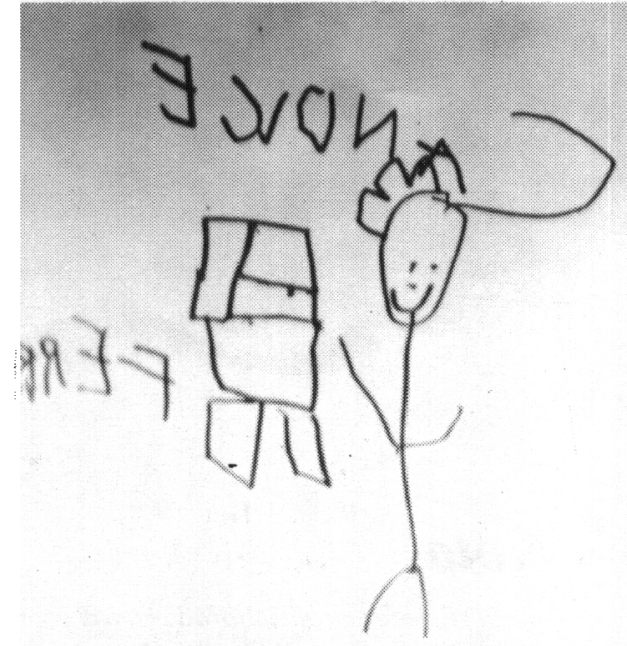

Figura 5

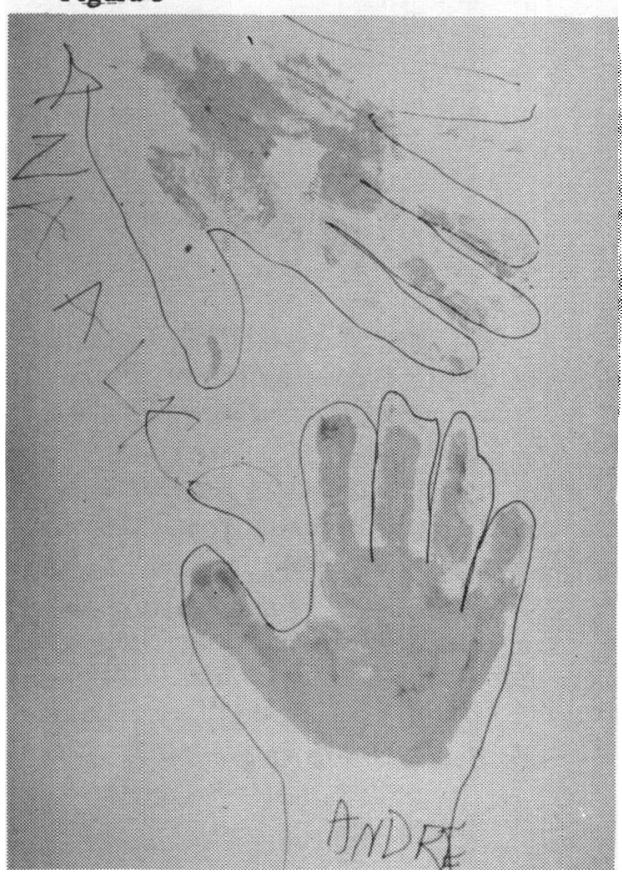

entrar em seu

mundo para tentar ajudá-lo a encontrar seus limites"

"A criança deficiente precisa do corpo do adulto

para se sentir segura e confiante"

\section{"Tentava acalmá-lo através da fala, do jeito, do toque"}

Numa das atividades desenvolvidas junta a " $A$ ", cobri as paredes, as mesas e o chão de nossa sala de atendimento grande e espaçosa - com metros e metros de papel Kraft para que tomasse consciência do espaço vivido através da marca deixada pelo rolo de tinta no papel. Entretanto, no lugar de expressar-se verbalmente em decorrência das experiências vivenciadas, " $A$ " voltava a encobrir os rastros de tinta com grafismos, divagando. Nesses momentos eu procurava entrar em seu mundo para tentar ajudá-lo a encontrar seus limites. Tentava acalmálo através da fala, do gesto, do toque. (A criança deficiente precisa do corpo do adulto para se sentir segura e confiante e ter ao seu lado uma facilitadora com muita disponibilidade) (fig. 3,4).

A atividade artística deve adaptar-se em suas diversas modalidades às necessidades psicológicas, específicas para acelerar o processo global de interação pessoa (fig. 5).

Entre erros e acertos e após várias tentativas frustradas de técnicas de organização, tentei motivar o lado da curiosidade da criança, passando para o artesanato em madeira. Esta atividade necessita de um certo controle, uma certa medida para sua execução, solicita seleção, classificação e seqüenciamento. "A" mostrou-se entusiasmado. Seu programa em terapias tornou-se estimulante e através dele começamos a usar a História da Arte como meio para conseguirmos melhores resultados. " $A$ " maravilhou-se com a visão das gravuras impressionistas, gostou da figura humana. Introduzi, assim, a pintura sobre tela, material que lhe trouxe muita satisfaçao. Escolheu entre outros um Rouault, elaborou imagens. Através da arte-sensibilização, pôde completar aos poucos a integração no sentir, no escolher, no fazer, no associar, num mesmo ato, recriar.

" $A$ " orgulhava-se de suas habilidades para a pintura, sendo que seus grafismos demonstraram maior organização e melhor controle motor.

As sessões de arte ajudaram a diminuir os transtornos de linguagem, a incapacidade de tolerar frustaçōes, abaixando os severos distúrbios de senso da realidade e a tendência a entrar em movimentação estereotipada. Associada a outras terapias, a arte-reabilitação foi uma provável causadora desse progresso. " $A$ " participou com suas produções de uma exposição numa Galeria. 


\section{Grupos de \\ arte-reabilitação}

Além dos casos atendidos individualmente, desenvolvemos atividadesem grupos de arte infantil, propiciados pelos estudos que fizemos das implicaçōes pedagógicas da teoria de Piaget à artereabilitação. Através da visão construtiva encontramos condições de integrar, numa mesma temática, os diferentes aspectos que compóem a personalidade humana. Por desenvolvermos uma atividade de expressão é a função simbólica do aspecto cognitivo que nos traz maior interesse, através de suas várias manifestaçōes: imitação, imagem mental,jogo simbólico, desenho, linguagem corporal, plástica, musical, oral. Essas formas de representação permitem a comunicação.

Para criar, a criança necessita de motivação e curiosidade, além de ter à sua disposição materiais específicos. $\mathrm{Na}$ criança deficiente, no entanto, esses fatores às vezes estão prejudicados. A criatividade na criança concretiza-se no brincar, associar, simbolizar, imitar, no fazer de conta. Apenas assim, aprende a compreender e controlar situaçōes e explorar-Ihes novas possibilidades, tornase consciente de si e do mundo. Revelerá, enfim, através da expressão artística, sua auto-imagem, onde comprometimentos físicos também serão revelados.

Para a fenomenologia, o esquema corporal é a expressão de estar no mundo. Merleau-Ponty é aquele que mais insistiu sobre a unidade intrínseca da percepção e da reflexão sobre si, que considera como funçōes corporais.

"O esquema corporal, diz MarleauPonty, é finalmente uma maneira de expressar que meu corpo está no mundo"; a espacialidade do próprio corpo é uma especialidade de situação; ele não existe "aqui", ele existe "através de situações" (Vayer, 1982, p. 32).

$O$ desenho da figura humana é o reflexo do desenvolvimento individual. A criança, que é capaz de sentir as relaçōes existentes entre as pessoas possui o sentido do seu fundamental, do movimento na formação da imagem corporal. Crianças deficientes, cujo movimento é danificado, desenham figuras humanas que refletem um conceito corporal imaturo, por vezes distorcido.

Um dos nossos objetivos nas sessð̃es de arte-reabilitação é, considerando a deficiência de movimentação, levar a criança a expressar cada vez mais e melhor sua auto-imagem.

Atendemos também crianças que, além da deficiência física, apresentam distúrbios visuais e auditivos. Cada caso exige uma atuação diferente de nossa parte, mas sempre visando o mesmo fim. As dificuldades motoras, porém, são as que mais interferem na produção gráfica ou pictórica, frustrando as vezes a intenção figurativa.

$\mathrm{Na} A \mathrm{ACD}$, desde muito pequenas, as crianças têm acesso a livros de arte. A história da arte passa a ser um substrato a ser relido, a re-interpretação permite que a criança construa livremente seus conceitos de arte.

Em 1991, foi elaborado um projeto de integração dos setores de arte-reabilitação da AACD e do serviço educativo do Museu de Arte Contemporânea da USP (MAC), através da museóloga Amanda Tojal, reunindo as propostas metodológicas de ambos e abrangendo os três níveis de conhecimento artístico; ou seja, História da Arte, análise da obra de arte e o fazer artístico. As atividades propostas visavam ampliar o potencial cognitivo e afetivo, projeto este que teve a participação também do grupo de pacientes adultos.

De modo a continuar com a proposta, foram realizadas uma visita à exposição "A mata" e um à 21" Bienal Internacional de São Paulo, cujas instalações possibilitaram um envolvimento perceptivo, sensorial e afetivo, e onde foi dada ênfase ao exame de obras tridimensionais.

Essas visitas ofereceram uma possibilidade enriquecedora que nos permitiu acompanhar o comportamento da criança fora das salas de terapia, além de proporcionar grande alegria aos pacientes, social e individualmente. A arte muitas vezes a única forma de comunicaçăo viável para eles.

Alguma coisa enigmática acontece com quem se envolve com a Arte. É uma lição de vida que recebemos de nossos pacientes, criar e ressurgir em novas imagens.

\section{Nota}

(1) Este textofoi elaborado coma supervisāo do Dr.J.A.Frayze-Pereira: Professor do Instituto de Psicologia da USP.

\section{Bibliografia}

DIAMENT Aron, CYBEL Saul. Neurologia Infantil Lefévre - Paralisia Cerebral. Rio de Janeiro, Livraria Atheneu, 1990.

DILEU, Joseph. A Interpretação do Desenho Infantil. Porto Alegre, Arte Médicas, 1985.

PEREIRA, Regina de Castro. Espiral do Símbolo Arte como Terapia. Sāo Paulo, Ed. Vozes Ltda, 1976.

VAYER, Pierre. Criança Diante do Mundo. Porto Alegre, 1984. 